\title{
Coupling BIM and Game Engine Technologies for Construction Knowledge \\ Enhancement
}

\section{${ }^{1}$ Buhammood A.H., ${ }^{1}$ Abanda F.H., ${ }^{1}$ Garstecki P., ${ }^{2}$ Manjia M.B., ${ }^{2}$ Pettang C. and ${ }^{3}$ Abdullahi A.M.}

\author{
${ }^{1}$ School of the Built Environment \\ Oxford Brookes University \\ Gipsy Lane Campus \\ OX3 0BP \\ ${ }^{2}$ Department of Civil Engineering \\ National Advanced School of Engineering, \\ The University of Yaoundé I \\ P.O. Box. 8390 \\ Yaoundé, Cameroon \\ ${ }^{3}$ Department of Quantity Surveying, \\ Faculty of Environmental Design, \\ Ahmadu Bello University, Zaria, Nigeria
}

\begin{abstract}
Interactions and collaboration between parties in a construction project are often characterised by misunderstandings and poor information exchange. Game engine technologies, when employed with Building Information Modelling (BIM), can help address these shortcomings. Quite often, the visualisation capabilities of BIM models are not explored fully partly because of its limited interactive capability. While game engines are powerful in visualisation and interactions in the gaming industry, the literature suggests a lack of understanding of the applicability of the same in construction. This study investigated the potential of the use of game engines in construction practice which culminated in a framework that can guide the implementation of the same in enhancing interactive building walkthroughs.
\end{abstract}

Keywords: BIM; Collaboration; Computer game engines in Construction; Interactivity; Performance; Project Understanding; Unity; Visualisation.

\section{INTRODUCTION}

Construction projects require collaboration and interaction amongst stakeholders representing different disciplines to deliver the final product. Also, the industry is responsible for a significant global economic output, which is forecast to reach $£ 13.56$ trillion in 2030, rising by $£ 6.2$ trillion from $£ 7.36$ trillion in 2015 (GCP and Oxford Economics, 2015). However, this growth is hindered by challenges that may often be attributed to low productivity which is in turn linked to poor project understanding and interaction between project parties/teams (Serror et al., 2008; Crotty, 2012). This is further exacerbated by defects or lapses in the communication chain, and insufficient 
information exchange and loss of important data (Aydin and Schnabel, 2014) that has become too common in construction process. When communication is not systematic and hindered, then the interaction of project participants can be limited. Serror et al.'s (2008) position on this is instructive. They posit that poor interactions at any project stage could gradually build up to significantly affect all ensuing stages, resulting in quality, time and cost inefficiencies.

Construction projects typically revolve around the client/end-user needs and wants, so it is essential that professionals working in the construction industry work in collaboration and supply these requirements in the most effective way (Kamara, Anumba and Evbuomwan, 2002). The design project phase is sometimes treated as separate from the actual construction process, and hence project teams gravitate to work in isolation, leading to conflict and disintegration (Baiden, Price and Dainty, 2006). In addition, certain procurement practices also hinder collaboration thereby contributing to the poor performance of projects (Baiden, Price and Dainty, 2006).

The literature suggests that $30 \%$ of all construction capital is not employed efficiently for construction purposes due to poor management during projects (Uyen (2003) cited in Nguyen, Ogunlana and Lan (2004)). Poor design capacity and frequent changes are also consistently ranked as the top critical factor causing project failure in Nguyen and Chileshe's (2013) study. The issues mentioned in the preceding sentences are partly related to lack of project understanding which consequently leads to poor interaction between project teams and to loss of significant data (Serror et al., 2008; Aydin and Schnabel, 2014). Additionally, professional and non-professional project team members comprehend the design and complex project information differently, and therefore, visualization methods can better enhance team members understanding of projects.

Several initiatives have been proposed by researchers and professionals to tackle these shortcomings, one of which is by integrating BIM technologies into projects, to facilitate a new approach to gather, process and utilise information across the project activities (Reddy, 2012). BIM is often regarded as a revolutionary tool that would enhance the construction project workflows by improving collaborative working and information exchange throughout the project lifecycle (Abanda et al., 2015; BSI, 2010; Edwards, Li and Wang, 2015). Conversely, some researchers believe BIM to be primarily utilised as a design tool (Bille et al., 2014; Holness, 2006), and hence the benefits associated with BIM application would mainly be related to designers/professionals involved in technical construction aspects (Mitchell et al., 2012). Stakeholder's involvement from early stages to completion is crucial to, ensure they are aware of the potentials, understand the implications, enlist their support and commitment, collect their inputs, set communication channels and facilitate collaboration, thus contributing significantly to project success.

Game applications contain specific 3D features that enable 3D visualisations of building models, and offer users the ability to navigate within them and in turn grants the possibility for both professionals and non-professionals to experience the building in operation prior to construction (Barwise et al., 2010; Mitchell et al., 2012). This visualisation experience may also serve to enhance an inexperienced and non-expert client or end-user's understanding of the project, allowing them to better communicate their feedback to the project team, hence leading to less frequent changes and associated time/cost overruns.

Studies have shown that computer game engines could be used together with BIM to extend the capability of building models into highly interactive 3D virtual environments that could provide interactive construction applications that are beneficial 
to both professional and non-professional users (Bille et al., 2014; Edwards, Li and Wang, 2015). These game environments offer a highly interactive user experience that allows communication with and responses from objects within the interface at an easy to learn manner (Yan, Culp and Graf, 2011). There is potential therefore to apply this to provide non-experienced users with the opportunity to visualise the model and interact in an immersive manner, a capability that is not available using the current BIM-based applications (Holness, 2006).

The utility of this approach is argued on the premise that project team interaction and collaboration can be improved via applications that facilitate better project understanding and information exchange, consequently improving the construction process. It is also capable of helping clients to better understand building models before construction commences. The purpose of this study was therefore, to investigate the potential of using game engines in construction practice, with a focus on its applicability, benefits and limitations. This also enabled the development of a framework for adopting game engines in construction practice.

\section{LITERATURE REVIEW}

There are many applicable technologies for enhancing the process and product of construction. Understanding their differences in terms of their application, benefits and barriers is essential when adopting them newly for construction practices is important (Bille et al., 2014; Tomala, 2017; Xue et al., 2018). The section begins with a review of related technologies, crucial to this study.

\subsection{Augmented Reality (AR)}

Augmented Reality (AR) employs the functionality of three-dimensional environments that may be explored and interacted with in person. It superimposes digital information from three-dimensional modelling on the existing physical environment in a way that allows the virtual elements to appear as though both environments coexist (Dunleavy and Deady, 2014). Similarly, AR employs the features of a digital display, sound qualities, textual data, and effects to provide the user an enhanced real-world experience (Loijens et al., 2017).

AR can be applied to benefit a project in many ways. Some of the areas of application include accelerated movement to site through improved health and safety training, and design development (Behzadi, 2016). This is achieved by creating a unique knowledge sharing experience to both the experienced and non-experience project participants, offering exposure to the physical characteristics before it is completed, and the opportunity to locate flaws in the project at a safe, hazard-free environment (Lin et al., 2013). Some AR's applications in construction have effectively enhanced, scheduling and project progress tracking (Wang et al., 2014; Park et al., 2013; Zaher, Greenwood and Marzouk, 2018) and researchers have noted its potential to help understanding the project process with less ambiguities, better communication of intent (Pejoska et al., 2016; Behzadi, 2016) and safety management (Wang and Dunston, 2007; Chi, Kang and Wang, 2013).

\subsection{Virtual Reality (VR) Systems}

Virtual Reality (VR) systems are based on a similar concept to AR, where a 3D computer-generated simulation of an environment may be explored in a seemingly real, physical manner using special digital equipment, that include a headset fitted with a display, and gloves or a control stick fitted with sensors (Whyte, 2003). VR technologies comprise motion, visual and auditory feedback sensors, but may be 
designed to include other types of sensors. Figure 1 shows a worker being trained on safety management using VR technology (Cyra, 2018).

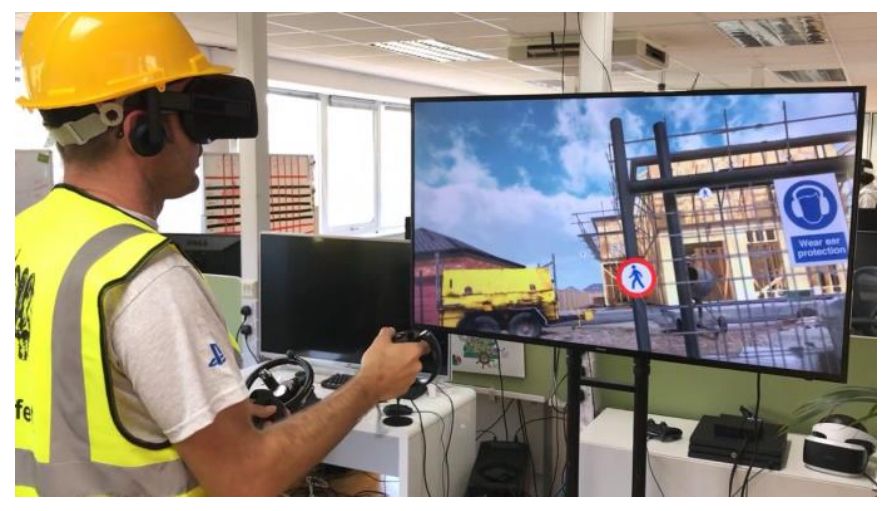

Figure 1: Construction Worker safety training using VR technology (Cyra, 2018)

The benefits of VR technology are similar to those aforementioned under AR (Behzadi, 2016), with the main focus being to address project failures that arise due the lack of ability, accessibility, and experience of field workers and consultants (Ahmed, 2018). VR may be integrated within construction projects to allow the project team to truly visualise and experience the end as-built project before it is built (Tomala, 2017; Ahmed, 2018). This allows for a better comprehension of the scale of project and the evaluation of different scenarios related to project management (Fernandes et al., 2006), hence reducing the risk of late design changes and avoiding cost creep prior to construction commencement (Tomala, 2017).

According to Peters, Postlethwaite and Wallace (2016), the working skills of labourers at certain tasks can be enhanced by providing VR-based training. Moreover, studies in using VR for safety education to promote a healthy and safe working environment, reported significant reductions in the rate of accidents as a result of using VR technology (Bhoir and Esmaeili, 2015). Perhaps the most significant benefit in application of VR technology is the visualisation of a project model with all its parametric information, unlike with 2D CAD drawings (Ahmed, 2018). VR allows for site work to be planned, monitored and controlled more effectively through detailed visualisation (Kamat et al., 2010).

\subsection{Game Engine Technologies and BIM}

Recent advancements in technology in terms of software efficiency and hardware capacity have increased the accessibility of virtual environments (Preda and Jovanova, 2013). However, the development of these interactive environments is often characterised by its time-consuming nature and technically difficult process (Smith and Trenholme, 2009; Bille et al., 2014). Game engine technologies offer an alternative approach to creating virtual environments. They provide much of the functionalities needed for a virtual environment, whilst minimising the associated costs (Marks, Windsor and Wünsche, 2007).

A computer game engine is a software platform that assists developers/designers in building user-friendly games (Marks, Windsor and Wünsche, 2007). Edwards, Li and Wang (2015) state that game engines are utilised due to their effectiveness in offering users intuitive control (simple enough for non-professionals), immersive 3D technology, and network capacity to accommodate multiple users in a simultaneous manner. Game engine environments are subjected to comprehensive and robust testing 
to provide tools that allow for model reusability (Trenholme and Smith, 2008). This forms an effective tool to reuse building models in computer game technologies, providing basic virtual settings that allow designers to import content such as geometry and texture as applicable.

Game engine technologies can be useful within the construction industry, but the appropriate scale for their use is unclear being borrowed from another industry. The 3D and data rich nature of BIM models means they are valuable sources of information. Hence there are ideal for constructing virtual environments in game engines. Game engines integrated with BIM created models "show a great potential for presentation, visualisation, education and simulation" (Bille et al., 2014). Figure 2 illustrates a BIM project model being visualized through Unity game engine (VIM AEC, 2017).

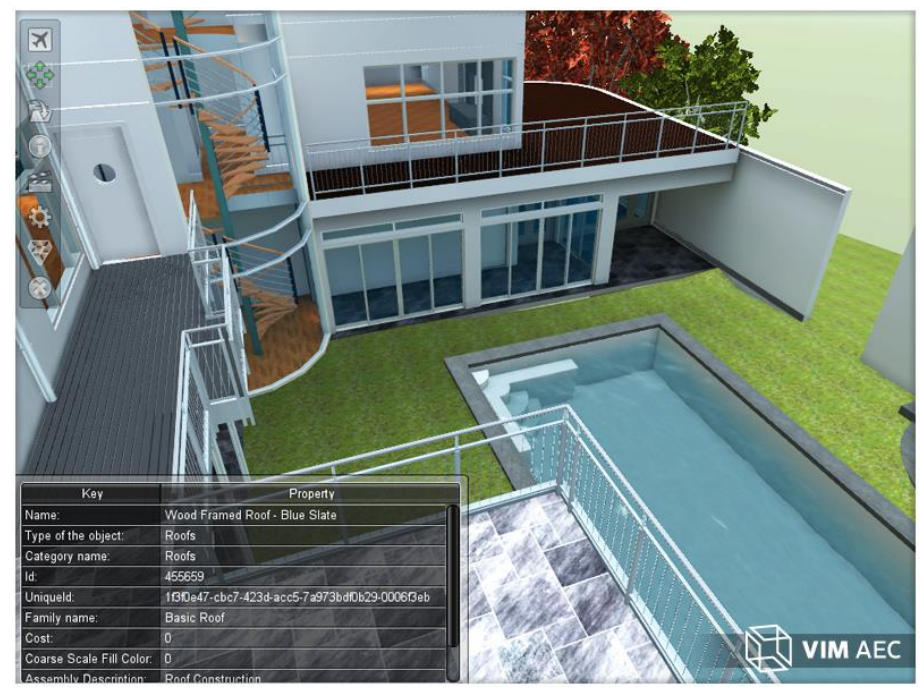

Figure 2: A BIM model exported from Autodesk Revit and visualized on the Unity game engine platform (VIM AEC, 2017)

A combination of BIM and game engines may potentially improve understanding through better information exchange, and collaboration amongst project parties, hence it can be detrimental to project success. The 3D nature of BIM models and the valuable information source they offer make it ideal to match with game engine's ability to build virtual environment (Bille et al., 2014). Nevertheless, limitations are imposed by the fact that BIM is mainly used as a design tool (Bille et al., 2014), hence the benefits associated with BIM application would appeal to professionals involved in the technical aspects of construction (Mitchell et al., 2012). Moreover, Holness (2006) argues that even though BIM models present structures in greater detail, photo realistic lighting, and surface rendering in contrast to $2 \mathrm{D}$ drawings, they lack in providing nonprofessionals the ability to interact with surroundings. Contrarily, computer game environments provide a highly interactive experience, allowing the user interaction with and responses from objects within the environment in an easy to learn manner (Yan, Culp and Graf, 2011; Parise and Crosina, 2012). A review towards understanding the applicability of BIM and different Game Engines addressing the relevance to practice is presented in the sections following.

\subsection{Some selected examples of game engines}


A Comprehensive review of game engines to realise virtual environments have been conducted in (Jacobson and Lewis, 2002; Trenholme and Smith, 2008; Zyda, 2005). These efforts will not be duplicated here. However, the most recent and popular game engines will be examined, These are the XNA framework (www.microsoft.com), CryEngine (www.cryengine.com) and Unity (www.unity3d.com). Furthermore, these selected game engines have recently been generating interest amongst professionals and also highly relevant to construction practice.

Microsoft XNA Framework: The Microsoft XNA framework was first released in 2006. It was developed by Microsoft over their .NET framework to provide a common environment for game development (Bille et al., 2014). The XNA game studio helps create games that can be played on Windows Phone 7, Windows-based PC's and Xbox 360 consoles (Microsoft, 2019). The latest stable version of the XNA framework is version 4.0 and was released in October 2010 (Microsoft, 2019). After the release of Windows Phone 8, Windows 8 and the Xbox One, Microsoft has stopped supporting the XNA framework (Bille et al., 2014). However, Yan, Culp and Graf (2011) utilised XNA in their research experiment, noting its compatibility with the Autodesk Revit.

CryEngine:The CryEngine game studio was developed by CryTek, limited in game development to Windows computers, and typically employed to develop high-end computer games such as FarCry and Crysis (Bille et al., 2014). As such, less powerful systems are unable to run games developed using CryEngine. Nevertheless, games developed on CryEngine can be deployed on major platforms such as Windows, PlayStation and Xbox (CryEngine, 2019). In Herrlich's (2007) experiment, interactive real-time visualisations were created using CryEngine, adding photo-realistic features to the game environment. The system was designed such that geographical information systems (GIS) data were imported into the game engine, to create a platform for presenting design ideas to clients and receiving feedback.

Unity: Unity Technologies first released their cross-platform game engine Unity in 2005, developed to run on computer devices using both Apple MacOS and Microsoft Windows operating systems (Bille et al., 2014). Games assembled on Unity can be deployed on several different platforms, such as desktop computers, mobile, consoles, TV, VR, AR and the Web, to reach the largest possible audience (Unity, 2019). Unity is available in both free for personal use and commercial for hobbyists/professionals, and version 2018.3.7 is the current stable release at the time of writing (Unity, 2019). Research experiments importing building data into Unity comprise cases where laser scanners were used to import historical buildings into unity (Merlo, Dalco and Fantini, 2012), and where Unity expedited the reuse of building floor plans (Preda and Jovanova, 2013).

Based on the review presented on three different game engines used in construction practices, it may be deduced that Unity would be better suited in applications within the construction sector. This is because it holds benefits in providing the user an option to choose from free or commercial versions, the ability to run and develop games on both Windows and MacOS, and the ability to deploy games for multiple platforms (Unity, 2019). Moreover, Unity recently announced collaboration with Autodesk, to support and enable models produced using Autodesk BIM tools (Revit, 3DS Max, Maya) to be imported seamlessly into the game engine where they can be visualised and experienced in real-time (Unity, 2019). Figure 3 presents a summary of the data transfer pipelines and multiple presentation platforms as supported by the game 
engines, developed by Bille et al. (2014) based on research findings, implying that Unity is better suited for BIM and game engine collaboration.



Figure 3: Summary of data transfer pipelines between BIM and game engines (Bille

et al., 2014).

\subsection{Applications and Benefits of Game Engines in Construction Practice}

An extensive review of game engines applications in construction have been examined in Edwards Li and Wang (2015). A summary of the main applications will be discussed in the ensuing paragraphs.

Fire evacuation simulation: Rüppel and Schatz (2011) carried out a study that investigated the application of game engine technologies to simulate a fire evacuation situation of a building's occupants. The game they created 'Serious Human Rescue Game' conducts simulations based on 3D information available from BIM applications, to explore the effects of building conditions on occupants' behaviour during evacuation (Rüppel and Schatz, 2011; Yan, Culp and Graf, 2011). Agent-based systems were used on some of the models in which virtual players were programmed using research-based parameters for the computer to simulate how computer-based players would try to evacuate the building (Rüppel and Schatz, 2011). Furthermore, the simulations were extended from being computer-driven to using human subjects driven game engine interactivity to explore their reaction and decision-making in a fire situation. In these simulations, Rüppel and Schatz (2011) introduced stimuli such as smoke machines and 3D optical screens etc. to bring a new dimension and create realistic game scenarios in an efficient way. They concluded that coupling BIM applications and game engine technologies should enable various stakeholders to simulate new, interactive and efficient building related scenarios.

Safety education simulations: BIM and game engines were used in collaboration in a study to educate students about health and safety in construction sites and evaluated their feedback to the approach (Dickinson et al., 2011; Lin, Son and Rojas, 2011). The game created by Lin, Son and Rojas (2011) conducts simulations based on 3D information available from a BIM model, where game subjects are allowed to explore 
the site freely and spot health and safety issues. The game interface allowed users to select the issues as they spot them, and identify what is wrong with the situation. The study achieved positive results that BIM and game engine collaboration. The study showed that the integration of BIM and game engines can enhance safety, noting from student feedback that game made it easier to learn about health and safety issues in a fun, more interactive manner (Lin, Son and Rojas, 2011).

Graphical simulation visualisation: Game engines are well-suited to visualise simulations in a graphical way by virtue of their real-time, high quality 3D graphics capabilities, and potential to manage 3D geometric data (Edwards, Li and Wang, 2015). El Nimr and Mohamed (2011) experimented with two different game engines to visualise simulations in a graphical way in two different scenarios. In the first scenario, a game was created to simulate the bidding process included in procuring a project at tendering stage. The game simulation generated jobs on a map where players could place bids for a job. In the second scenario, the game developed employed a real-life construction process where players were able to visualise the site and observe the construction process of a structure that was partly being constructed off-site (El Nimr and Mohamed, 2011). The components constructed off-site were transported to site for further assembly into modules used to build up the final structure. The overall construction process was simulated entirely by the game, to enable the site to be visualised by contractors looking to identify where cranes/machinery would fit during construction, as well as the yard where singular off-site components were put together into modules (Edwards, Li and Wang, 2015). The results obtained from the study made evident the benefits of graphical simulations in allowing users to visualise what goes on where, prior to or during construction.

Design Review: Design review systems that are currently used in industry such as the peer-review method, are argued to be inadequate in accommodating relevant stakeholders who may contribute reasonably to the process (Edwards, Li and Wang, 2015). For instance, a light box may be superimposed on the drawings to simplify the process of identifying disparities between various design elements. However, this process is often found to be tedious and hence not conducted efficiently or not conducted at all (Shiratuddin and Thabet, 2011).

Game engines on the other hand, would be better suited to facilitate real-time visualisation, by virtue of their $3 \mathrm{D}$ graphics and networking features that implement real-time user collaboration (Edwards, Li and Wang, 2015). Shiratuddin and Thabet (2011) used a game engine to develop a game prototype where several users can review and interact with a design simultaneously, access design information, and carry out basic 3D editing. Moreover, the game facilitates communication between users within the game and allows them to leave notes on the design model. They concluded predicting that this kind of system would enhance the quality of the design review process, making it more straightforward and efficient.

\subsection{Barriers of Game Engine Application in Construction}

Despite the benefits of virtual environments in enhancing collaboration through better understanding and learning of projects, there exist some challenges. Some of these limitations were identified in a study by $\mathrm{Gu}$ et al. (2009) who carried an experiment to evaluate the effectiveness of virtual environments in terms of design support, communication and teamwork. In terms of design support, 39\% of participants 
rated their experience as neutral (Gu et al., 2009), noting that virtual worlds have been found to be instantaneous to see objects being made, easy and quick to apply models and textures, and easier to understand the concept, whereas $39 \%$ were dissatisfied noting limitations due to issues with software compatibility (with other rendering software), and requirements for all players to be online (Gu et al., 2009). In communication, in synchronous communication was effective when all students were online and could share the information with each other. However, when the students were offline other communication media such as texting/emails was more effective in arranging for meetings. In terms of teamwork, $51 \%$ of participants agreed that it was difficult to work together as a group due to the absence of face-to-face meetings, whilst $25 \%$ disagree ( $\mathrm{Gu}$ et al., 2009).

Rüppel and Schatz (2011) describe the game development process as time consuming, since a large proportion of the 3D modelling work requires double execution, once by the architect/designer to create the parametric building model, and second by the game developer to create the 3D game content. Garrison and Kanuka (2004), as well as Shemla and Nachmias (2006) cited several researchers highlighting the challenges associated with collaborative working/design learning via virtual environments, listed as following:

- Human, financial and technical resources are required to support the model (Garrison and Kanuka, 2004; Shemla and Nachmias, 2006).

- Training and support must be offered to both instructors and students in learning and teaching facilities with respect to using the technology (Bates and Khasawneh, 2007; Murphy and Coleman, 2004).

- Discussions held in online communication maybe governed by certain individuals or groups, rendering teamwork ineffective (Murphy and Coleman, 2004).

- Consequently, students learning online expressed feelings of loneliness, exclusion, and frustration (Bates and Khasawneh, 2007; Murphy and Coleman, 2004).

Similar challenges may be associated with collaborative working in construction projects via game engine environments, leading to barriers in application. For instance, in Doughty and O'Coill's (2005) study, computer game technologies were found to benefit the participatory design process mainly through the visualisation and contextualising of the model but limited by traditional technological barriers. Nevertheless, these barriers did not entirely remove participants from the process, but only reduced their engagement. Handel et al. (2015) identified limitations of Unity in terms of 3D modelling, as it does not identify Non-Uniform Rational Basis Spline (NURBS) surfaces. This means that shapes must be arranged at a place where the NURBS surface is partitioned in the polygons. Additionally, bigger objects need to be split into smaller objects due to index buffer and limited vertices. Moreover, it is claimed that since Unity is incompatible with Autodesk's material library, additional software (3DS Max) is required to make the integration between Revit and Unity possible. However, with the new collaboration between Revit and Unity it is presumable that this issue may be resolved (Unity, 2019).

\section{RESEARCH METHODS}

\subsection{Overview of method}

The aim of the study is to explore how game engines can be used to enhance understanding of building projects. It involves design, programming, cyclic and 
iterative actions to evaluate the understanding and feeling of the end-users immersed in real-life construction project simulated in the BIM model. Achieving such an aim requires the employment of design science research (DSR) (Kotzé et al., 2015). Furthermore, Hevner et al. (2004) defined DSR as "a problem-solving paradigm which seeks to create innovations that define ideas, practices, technical capabilities and products through which the analysis, design, implementation, management, and use of information systems can be effectively and efficiently accomplished".

This project utilises BIM technologies as an information source in collaboration with game engines to create an artificial construct solution in the form of building model simulation and establish knowledge on the use of game engines within construction practice. According to Kehily and Underwood (2015), if research in BIM involves building up a new BIM solution, whether through a procedure or innovative change, it will be imperative to develop a practical research design such as DSR that empowers the researcher to develop the solution, and then evaluate it. BIM represents an innovative approach to thinking, project delivery and is considered a cultural change (Taylor and Bailey, 2011), hence it requires a practical approach such as DSR to facilitate development and evaluation of new solutions (Kehily and Underwood, 2015). The evaluation aspect of this study is conducted using a qualitative approach, based on simulation and observation by experts. The details will be discussed in the ensuing paragraphs.

\subsection{Design and development}

A game simulation was created using the Unity game engine interactive platform, which represents the artefact in this research. The simulation process employs a case study in the form of a standard BIM model as an information source to be exported from the Revit designer platform and imported into the Unity game engine interactive platform. A standard model was used because it is rich in information and developed using a standard BIM protocol. The sample project is the one that comes with Revit installation. Autodesk Revit provides sample projects that are not specific to a single profession, hence when viewed include all the details required by various professions, civil/structural, architectural, MEP etc. are provided, and are therefore well-suited for general use within the scope of this project. Additionally, Autodesk Revit was used to create a BIM visualisation walkthrough employing the same standard case study Revit model to facilitate data collection for the purpose of comparison with the game visualisation application.

The key software systems used in this step are Autodesk Revit and Unity. The first attempt to export a BIM model from Revit to Unity was conducted using the method suggested by Bille et al. (2014) depicted in Figure 4.

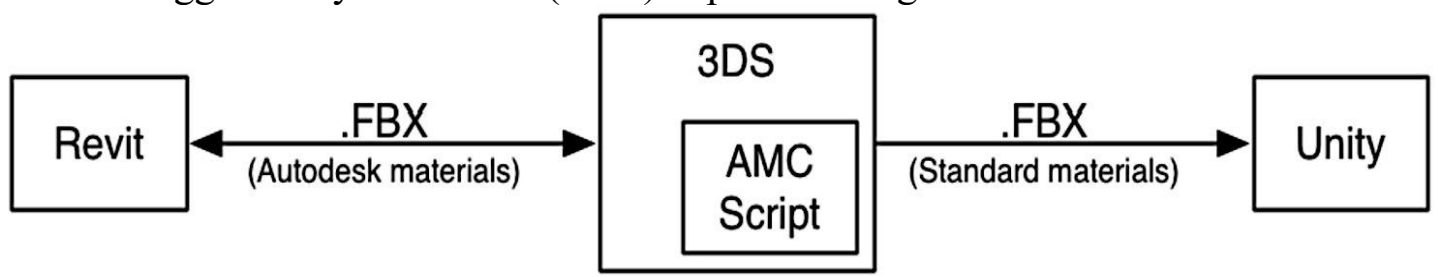

Figure 4: Revit to Unity process pipeline, reproduced from Bille et al. (2014). 
However, the resultant model from this conversion process depicted in Figure 3 in Unity was plain and without texture. It is important to note that these findings are corroborated by similar study by Li and Wang (2015) who experienced similar issues converting BIM models into Unity. Another approach based on the use of IFC and a plugin Tridify was used. Tridify BIM tools as a plugin to Unity can support export/import between Revit and Unity in IFC format (Tridify, 2019). The model is converted into IFC and loaded into Tridify as as shown in Figure 5.
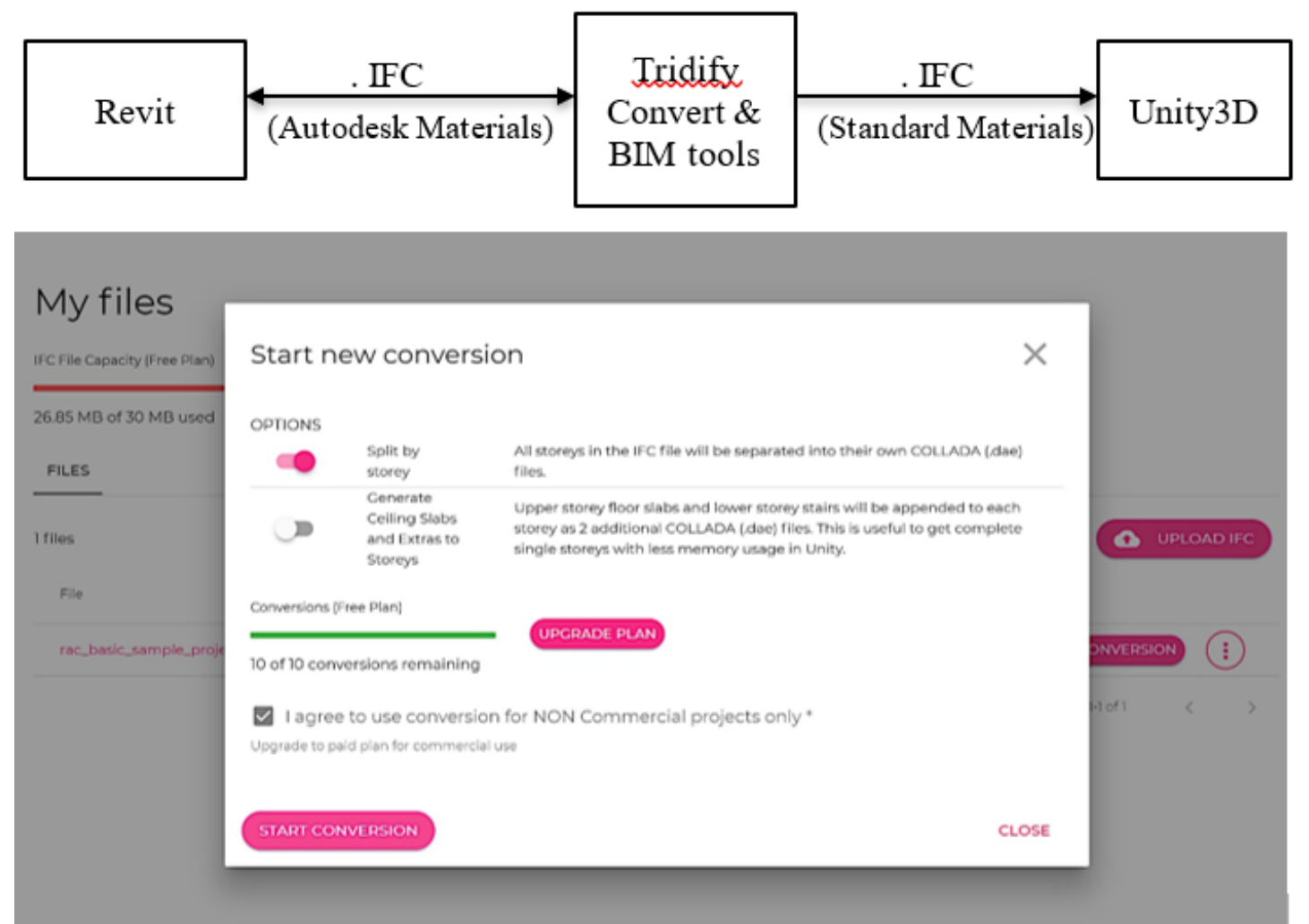

Figure 5 Tridify Conversion Process

The file capacity in the free version of Tridify is limited to 30 MB (Tridify, 2019); hence using larger size models was not possible. After the model was loaded and validated, the IFC Revit model was converted into a Unity compatible model as shown in Figure 6. 


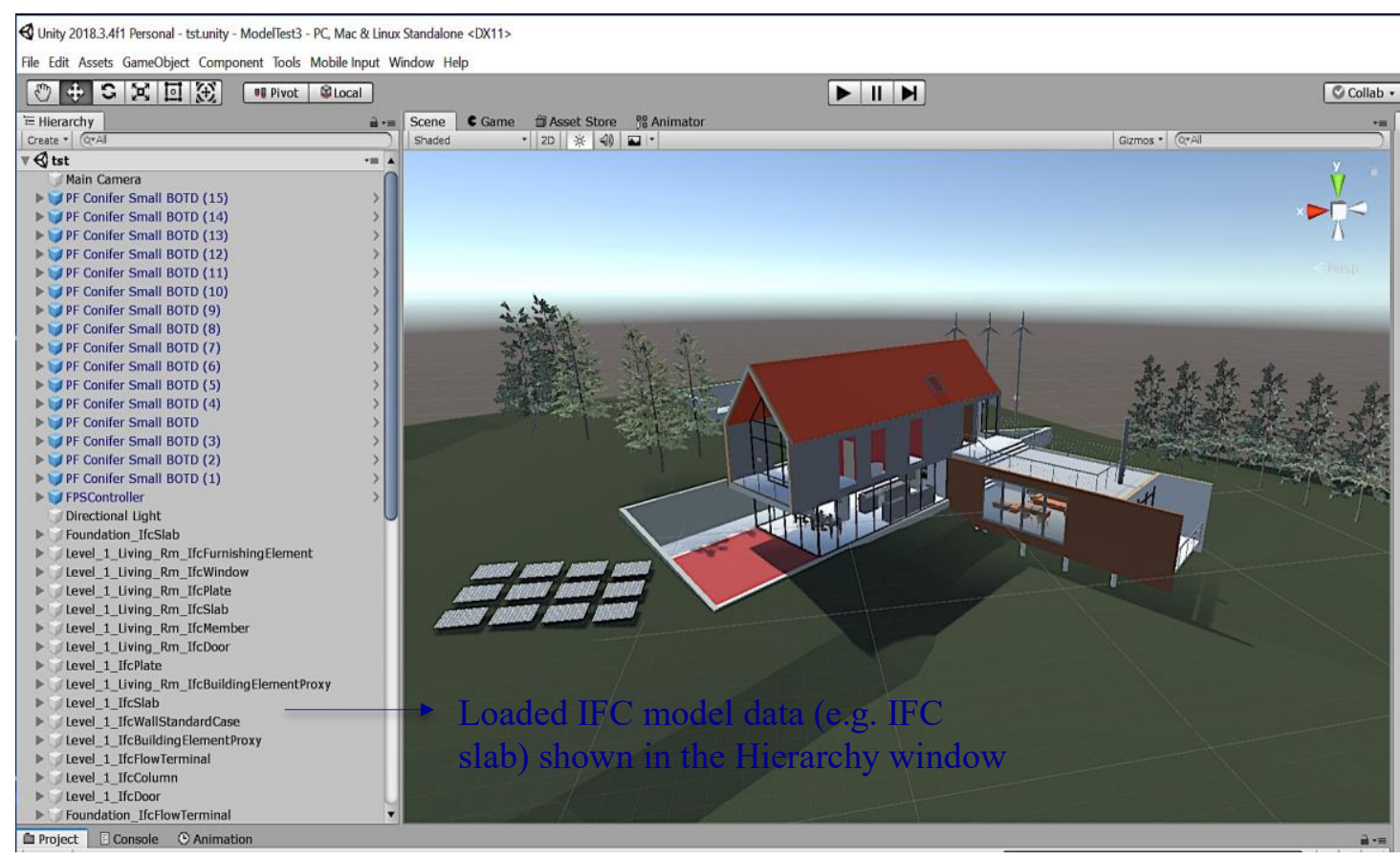

Figure 6: Revit BIM model imported into the Unity game scene

The loaded model shown in Figure 6 was modified, such that tree objects downloaded from Unity Asset store were placed to replace the ones originally loaded from the IFC BIM model, to add a realistic finish. The model may now be fully visualised within the game engine and developed to add interactive applications.

\subsection{Applications}

\subsubsection{Walkthrough application}

The three main activities conducted here is to create colliders, mesh colliders and adding First Person Controller (FPS). To facilitate having a walkthrough, colliders had to be created to define the physical edges of the game objects so that the game user would not fall through the site ground, or pass through walls, doors etc. The colliders and mesh colliders were added individually to each building game object including walls, windows, furniture, floors, and doors from within Unity (shown in Figure 7). 


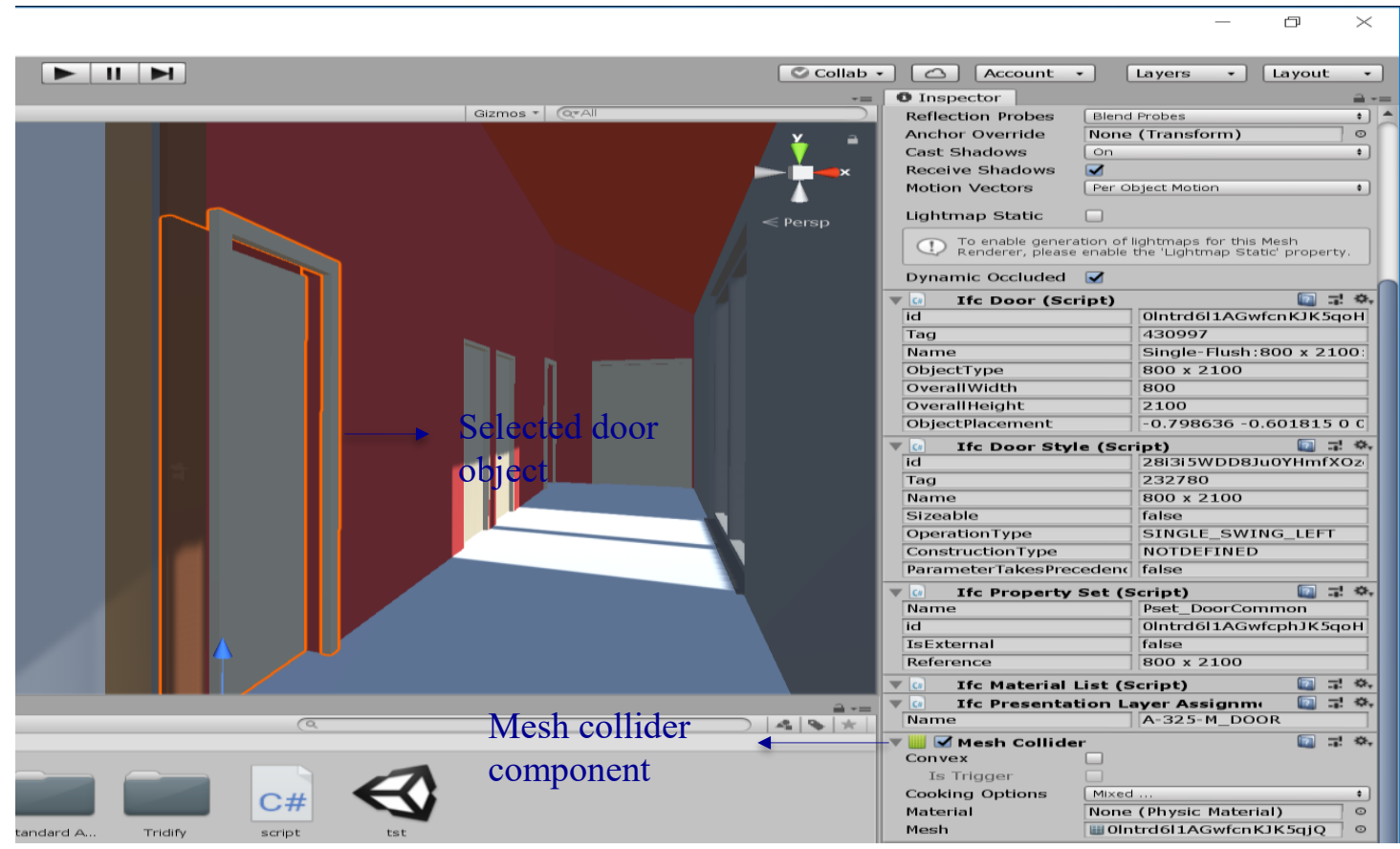

Figure 7: Adding mesh collider component to a door in the model

The next step illustrates adding a First Person Controller (FPS) that would enable the game application user to move around freely in the game via keyboard controls and experience the building through the eyes of the main character (See Figure 8). A first person camera system was chosen as it is more commonly used within games in the gaming industry, and because choosing an alternative camera system might lead to bad game control and having a disjointed game feel (Sabbagh, 2015). Sabbagh (2015) offers a full review on the difference between first-person and third-person game control, mainly stating that first-person provides a better sense of immersion, enabling better user reflexes and player bond to the game environment. 


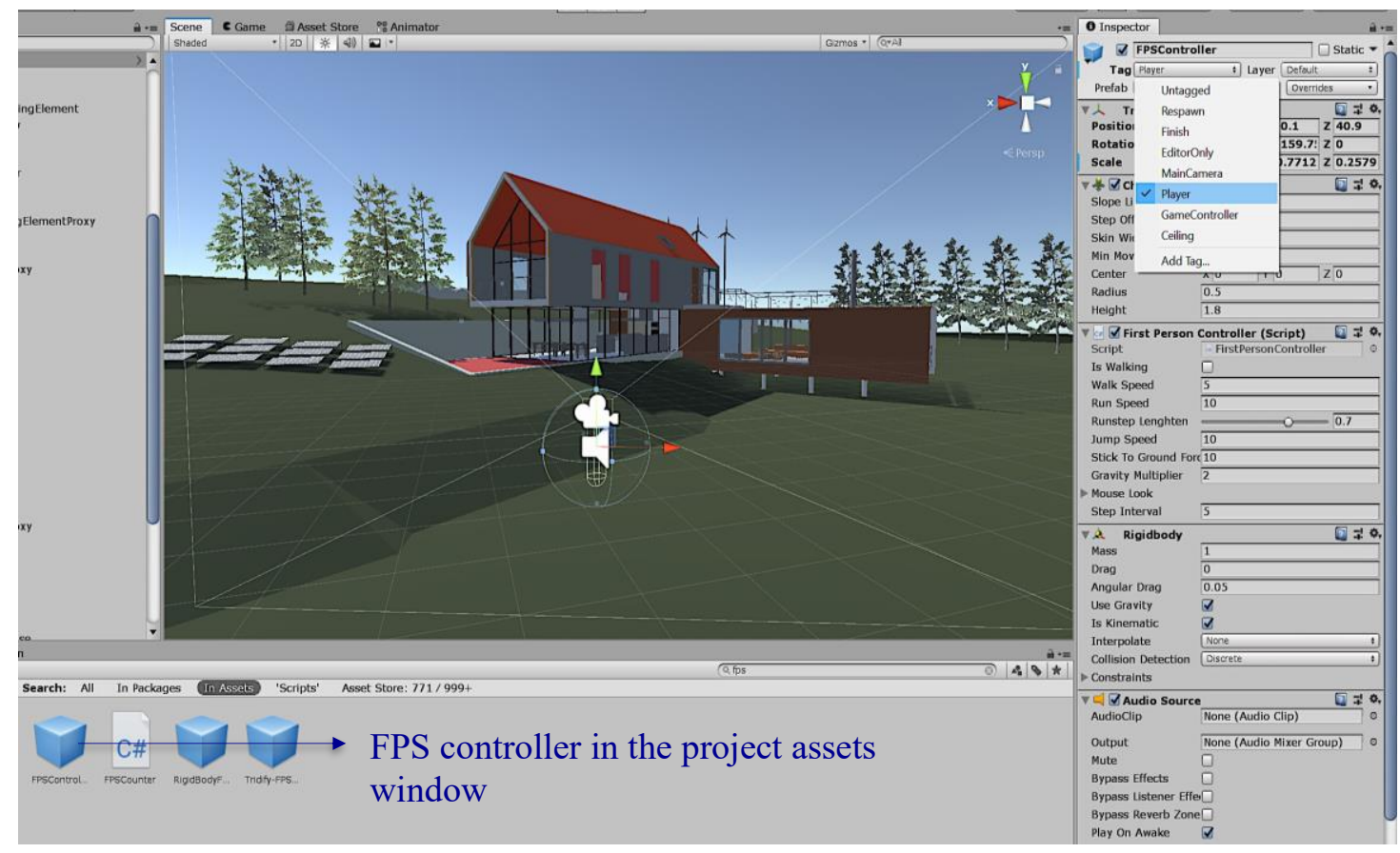

Figure 8: FPS controller added to game scene and tagged as 'Player'

A 'Player' tag was added to the FPS controller to facilitate creating the door opening application on trigger as described further in the section following. The FPS character controls may be summarised as follows: W - Move Forward, S - Move Backward, A - Move left, D - Move Right, Space - Jump, L-Shift - Sprint; Mouse Adjust Player camera view / direction.

\subsubsection{Door opening application}

This application is about the doors opening and closing when triggered by the game user's proximity during the walkthrough without any physical intervention or touch. A single door was selected to illustrate the steps to creating this application, however the same process was applied to all doors in the building model.

The first activity is to create a "door holder object".

In order to open/close a door, it must be rotated to swing outwards/inwards. In Unity, if a door were normally animated to rotate, it would rotate about its centre point, meaning the centre of the door would be the pivot point or centre of rotation. To solve this issue, a door holder object must be created as a parent object of the child door object, such that it acts as a hinge in a sense that when the parent object (door holder) is rotated, the door gets rotated (Jayanam, 2016). The left outer edge of the door object should be aligned with the centre point of the door holder object. Once the "door holder object" was created, it was resized to fit within the door frame, repositioned such that its centre point aligns with the left outer edge of the door, a trigger functionality was added and the trigger zone was resized to occupy the surrounding door area. This is captured in Figure 9. 


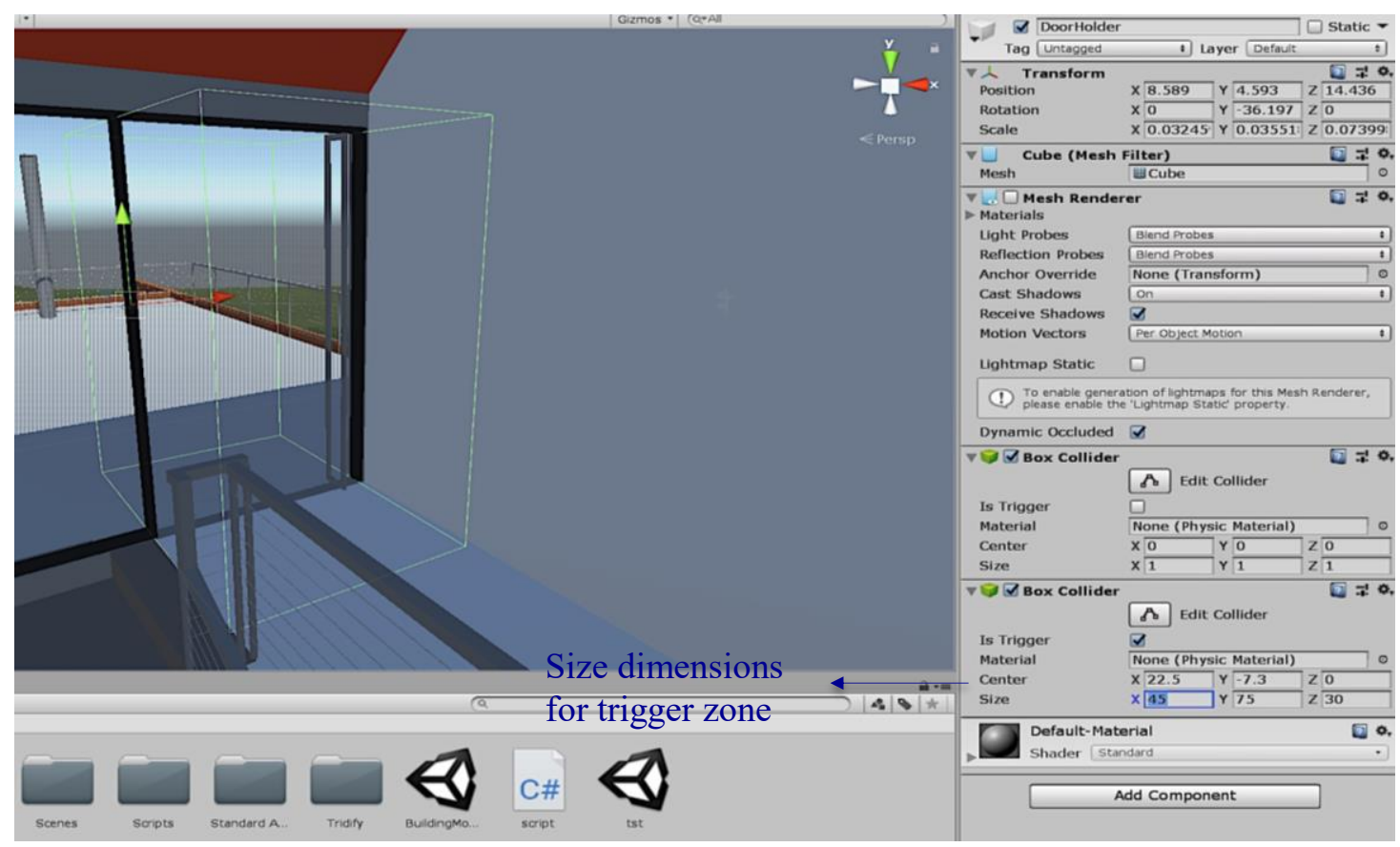

Figure 9: Resizing the trigger zone to occupy the surrounding door area

Lastly, the door holder object was moved up the hierarchy by dragging it using the mouse, so that it is a parent of the door object as shown in Figure 10.

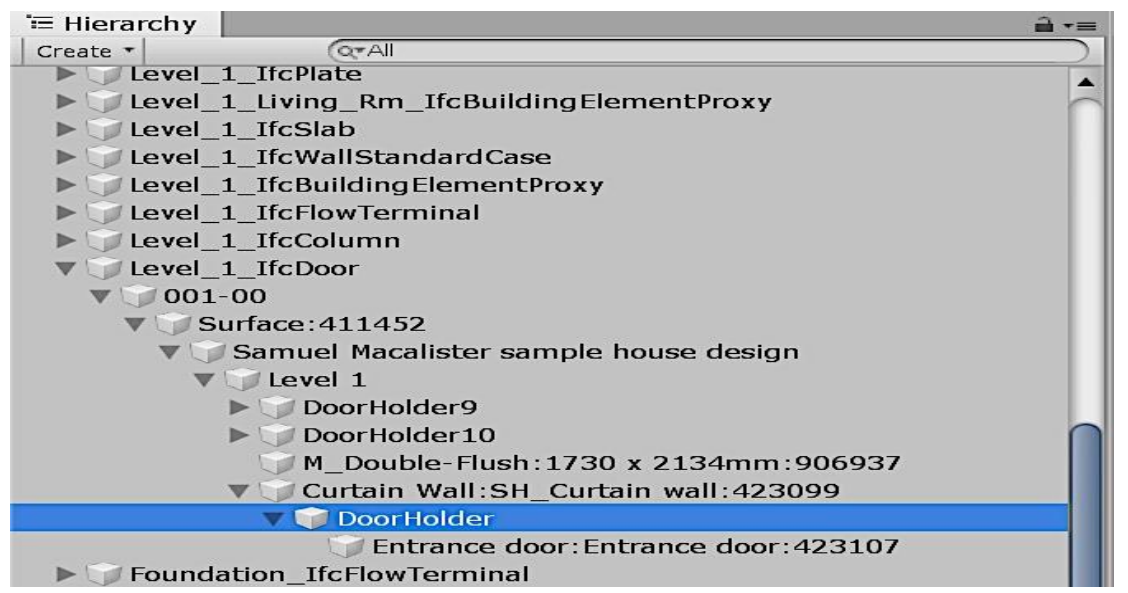

Figure 10: Door holder object as a parent of the door object

After the door holder is created and properly placed, the next step is to create a rotation animation for the door to swing open and close. They key activities in this step were creating a new animation file for the door holder, adding a rotation property to the created animation, then using the rotate tool to rotate the door between the open and close key frames in the animation created. A new animation was created using the animation function in Unity. The different animation states are presented in Figure 11. 


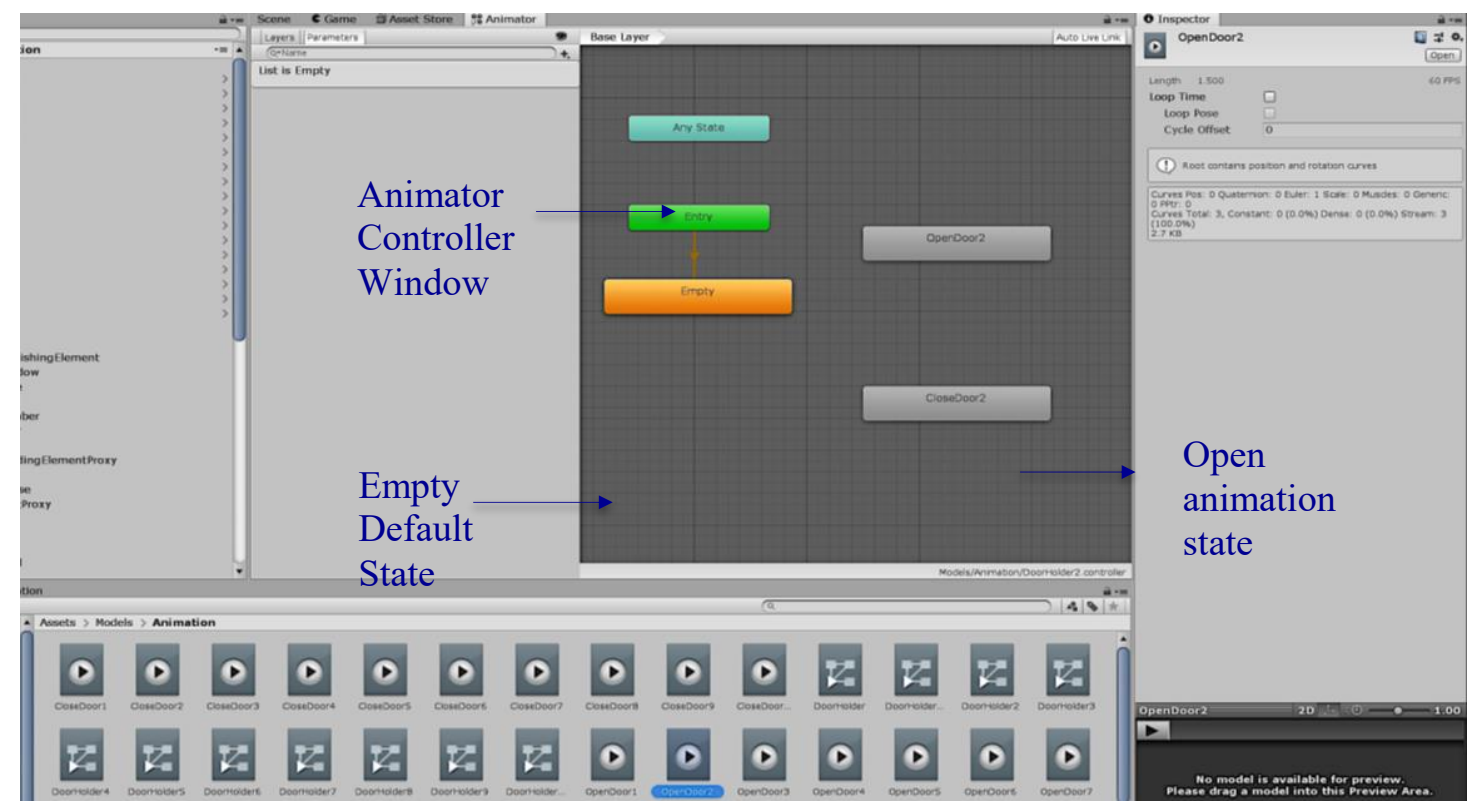

Figure 11: Boolean parameter created to facilitate transitions

To facilitate the application of doors opening/closing, a C\# script was compiled to activate the door animations created in the previous steps when triggered by the game user (FPS). They key activities in this step were, creating a script file and naming it 'DoorHolder', writing the code in C\# programming language (Language used in the Unity development interface), then attaching the script to the door holder object. The script file was then opened in visual studio, and the code was written in C\# programming language.

The C\# script (found under Appendix A) created to achieve the application of opening/closing doors may be interpreted as follows. A Public class 'DoorScript' was created to hold the objects and functions required in activating the door opening/closing application. Under this class a private variable '_animator' of type 'Animator' was created and initiated to 'null'. This variable was used to hold the animator controller, and call upon functions to set parameters within the animator controller as further described. The animator controller was called using the 'GetComponent $<$ Animator $>$ ' function and assigned to the member variable '_animator', which references the animator component created the door opening/closing animations were created.

In the 'OnTriggerEnter' function, when the trigger zone is entered by a collider object (FPS Controller in this case), an 'if function' checks if the collider object is tagged as 'Player'. If the collider tag is 'Player', the 'Open' bool parameter is set to true, and the transition between the between the 'Empty' and 'Open' animations states in the animator controller is activated to open the door.

In the 'OnTriggerExit' function, when the trigger zone is exited by a collider object (FPS Controller in this case), an 'if function' checks if the collider object is tagged as 'Player'. If the collider tag is 'Player', the 'Open' bool parameter is set to false, and the transition between the between the 'Open' and 'Close' animations states in the animator controller is activated to close the door. The 'Update' function was 
simply used to update the game scene frames as the animations are activated and during the game user movements. The game simulation was now fully developed, and ready to be deployed on an executable file.

\subsection{Demonstration}

This section contains screenshots demonstrating the working building model game simulation artefact created, both within the unity editor and the executed game version. Figure 12 shows the game run in the unity game editor from a first-person camera viewpoint presenting the building model through the eyes of the main character. Figure 13 shows the door opening during the game run when triggered by the player. Figure 12 and Figure 13 show indoor scenes of the game run from the created executable file.

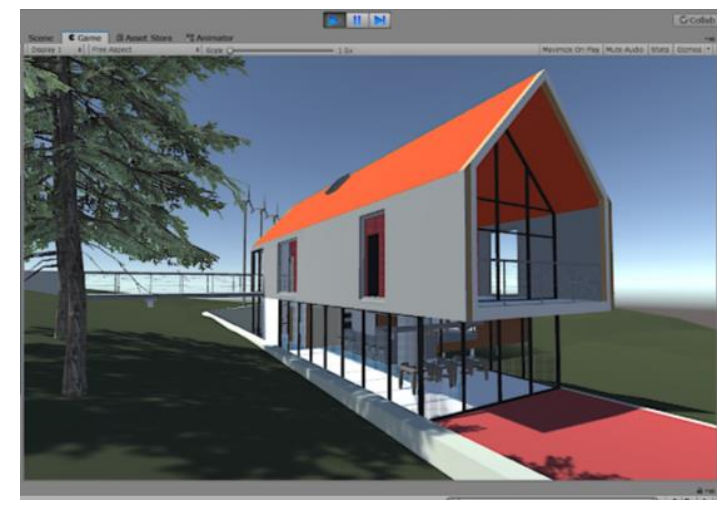

Figure 12: Game run from the FPS controller perspective

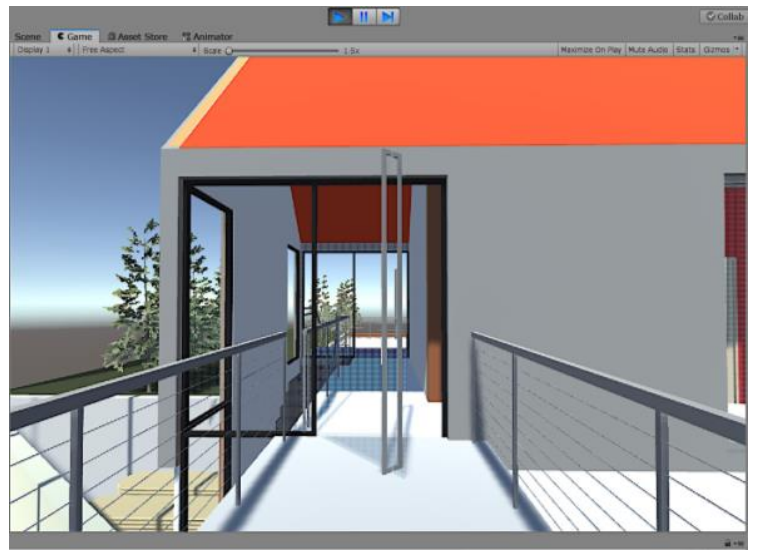

Figure 13: Door opening on trigger by the player during the game run

As the player approaches the trigger zone, line 12 of the C\# script (found under Appendix A) 'void OnTriggerEnter(Collider other)' is activated to check if the object approaching is tagged as 'Player' and activate the animator controller to open the door as shown in Figure 13.

The scenes shown in Figures $14 \& 15$, illustrate the game run in full screen from the executable file run on a windows platform, from a first person camera viewpoint, presenting the building model through the eyes of the main character. 


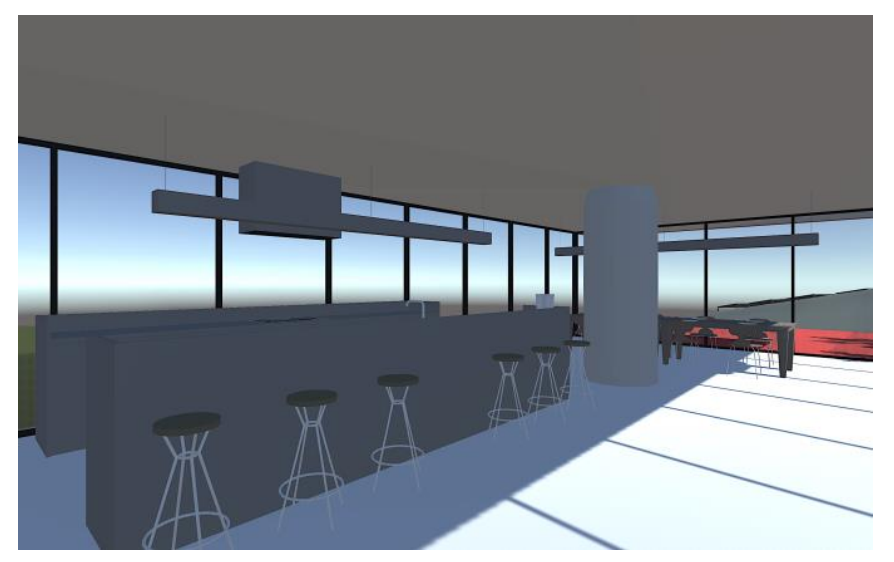

Figure 14: Indoor kitchen scene from the executable file

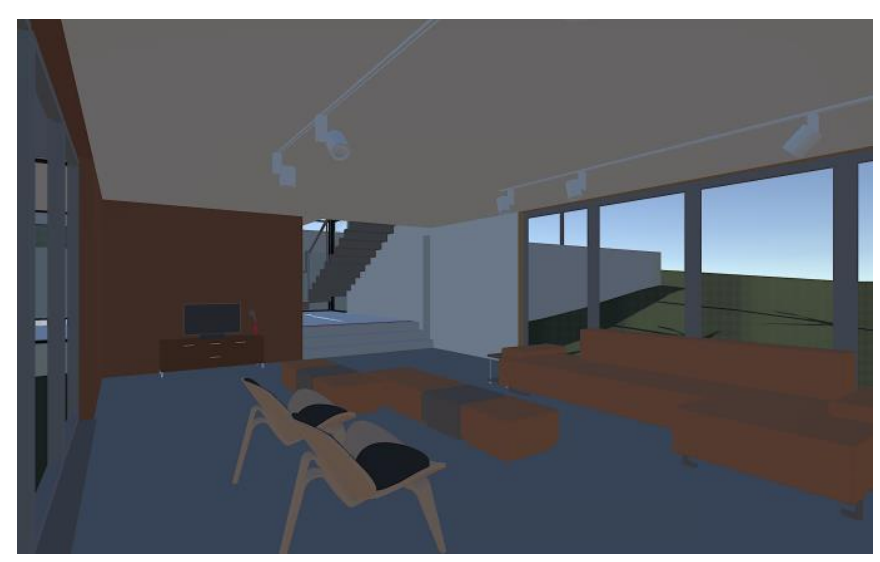

Figure 15: Indoor living room scene from the executable file

\subsection{Evaluation}

Observational data on the game simulation was collected, where the researcher personally observed the functionality of the artefact, to assess its practical applications, benefits and barriers and evaluate against intended requirements. This approach is practical since it enables the researcher gain an in-depth, rich understanding of the game simulation, and facilitates the development of new ideas or theories about system (McLeod, 2015).

Additionally, primary data was collected via structured interviews to validate and enhance observed findings, and to gain valuable information from both professionals and non-professionals on their perception, understanding, and applicability of the game simulation. This complemented the data obtained by observation. Interviewees were presented with both the Game Model Visualisation approach and the BIM Visualisation approach, then asking questions to capture the participants' model interactivity, understanding of model, how well it facilities collaborative work, level of interest, applicability to construction and recommendations for improvement. 
The data obtained from interviews is analysed to complement the observed findings and discuss their validity against the perceptions of interviewees. Moreover, evaluation is conducted as a part of the Design Science Research Method activities (Peffers et al. 2008), by asking questions such as: How well does the artefact work? Is the user able to do a walk through? Do doors open automatically on trigger? Where can this solution be applied? These methods facilitate the development of further research ideas, based on a rich understanding of the game simulation.

\section{FINDINGS AND DISCUSSION}

To facilitate understanding the findings will be discussed in alignment with the research objectives.

Firstly, this study built on previous studies about the existing game engines and reviewed the leading ones in section 2. It emerged from the review that the leading game engines are Microsoft XNA Framework, CryEngine and Unity.

Secondly, the next finding is about the applications of game engines in construction.

Based on the literature, the main applications of game engines in construction are Fire Evacuation Game Simulations, Safety Education Game Simulations, Procurement and Tendering Simulation, Interactive Visualisation Simulations, Visualising Offsite Construction Practices, Design Review by Multiple Users.

Through the observation of the animation of the building model game simulation it was noticed that several applications beyond the scope of a walkthrough, and door opening/closing application, could be developed in the system artefact. To facilitate the development of complex applications that enhance collaboration in project activities, scripts/codes were found to be the most practical approach to implement personal gameplay features, events and modify the behaviour of game objects and responses as required.

In addition to the literature findings uncovered in section $2.4,2.5$ and 2.6 results obtained through observation and interviews will be discussed in sections 4.1-4.3.

\subsection{Applications in construction practice Findings from Interview}

Further to the applications derived from observation and literature findings; the discussion with interview participants provided an interesting insight into potential applications of game engines based on their understanding of construction and those that match their field of experience. Several participants have suggested that VR technologies can enhance game visualisation of a building model (Participants: A, C, \& D), where VR can be incorporated into game visualisation to allow people to walk into a space and have a feel of the space / appreciate it. Participant A stated that "The game on a computer helped me better understand the space, but seeing it through my own eyes on a VR as though I was standing there, would provide an even better understanding". In the field of quantity surveying, both Participants A \& D thought that a Costing / Valuation application integrating VR game visualisation, where a quantity surveyor (QS) could walk around the building spaces during construction, to evaluate the amount of work completed and produce valuations. Moreover, when making changes/additions to the design, the game would reflect how that would affect the cost 
and the QS would be able to inform the client of any cost implications. Participant D stated that this would make performing valuations "more creative and easier".

Participant A suggested a number of applications in regards to VR coupling with game visualisation, summarised as follows:

- Health and Safety Education Application - Simulations where users would identify hazards on a construction site via visualisation, then click and select the issue. The same application was derived from observations and literature findings (Lin, Son and Rojas, 2011).

- Services Design - Using visualisation to have a feel of how the different service pipes are able to go through the ductwork.

- Offices Design - Using game visualisation to better understand the layout, lighting requirements and partitioning within the office, to see how the offices would look like and where people are able to work.

- Crowd Control Design - Game visualisation would help design crowd exit points and determine their feasibility, as the designer is able to estimate the distance and where people can pass through.

Furthermore, two participants put forward a similar idea using game visualisation in the field of sustainable design. Participants C \& E put forward the idea for an Energy Analysis application where if a user walks into a room, the walls or windows could get red (higher energy use / hotter) or blue (lower energy use / cooler), indicating the energy usage. This would point the architect to what materials are causing the issue and indicate the requirement for size / material change. Participant E further suggested implementing Mouse Click Controls to zoom into a particular detail for structural / architectural editing purposes, and to navigate into a particular room e.g. kitchen, without having to follow the entire building layout. However, the participants acknowledged that since the game visualisation application created in this research aims to be realistic in presentation, click controls would be better suited for future applications as per requirement.

On the other hand, several participants have pointed that game controls may not be familiar to people who do not play games, necessitating time to educate and train users. Participant B suggested developing an initiative to make learning the buttons and their functionalities easier. Moreover, Participant F suggested that implementing Better graphics would enhance the quality of the visualisation, stating, "With current graphics, it is more like a game than it is showcasing the design".

The common thought perceived from interview discussions on BIM applications, is that BIM application would be better suited for designers as they already appreciate the building space/features/layout and understand it without the need to visualise it. Designers would mostly need to integrate their drawings into the design, so using BIM applications would be sufficient for designers but not clients. This is consistent with findings of Mitchell et al. (2012) who suggested that the benefits associated with the use of BIM mainly apply to experts concerned with the technical and practical aspects of construction.

\subsection{Benefits of game engines in construction practice}

\section{Findings from Observation}

The game provided users with several functionalities that enhance their experience and understanding of the hypothetical project. The game offers the benefit of visualisation via a walkthrough application, allowing users to visualise and explore a structure prior to or during its construction in a more intuitive approach and immersive 
experience. Additionally, the game provides interactivity via the doors opening/closing when triggered by the player, which adds an element of reality to the user experience. These can serve to enhance the user's understanding of the project and building components, which facilitates collaboration amongst project stakeholders. Moreover, users exploring the building model through the game can communicate their feedback and comments in a face-to-face manner or via other communication media (emails, video calls etc.) as the model is explored. Rüppel and Schatz (2011) reported similar findings, stating that the game brings new dimensions and creates realistic game scenarios simulating real construction scenarios in an efficient way.

Nevertheless, both BIM and game engines are said to bring a more intuitive, immersive approach to view/explore buildings prior to or during their construction, compared to the static generally used 2D drawings (Yan, Culp and Graf, 2011). However, the walkthroughs that exist within BIM tools like Revit are usually in the form of a recorded video presentation where the user is able to click to move from one scene to another. Whereas in game engines like Unity, a major benefit is that the user possesses control over the player's actions and can explore freely without the limitations set by recorded presentations. Moreover, design review systems found in BIM software, such as the peer review method has been found tedious and hence is not conducted efficiently (Shirattudin and Thabet, 2011).

Furthermore, unlike BIM software, game engine offers potential benefits in using the script system providing flexibility to develop several applications beyond what is available in the standard game engine system (i.e. doors opening/closing, model editing etc.), usually in the form of plugins that enhance the game functionality. Overall, game engines and their applications can serve to enhance the quality of processes/activities within construction project, making them more straightforward and intuitive.

\section{Findings from Interviews}

The interview questions aimed to capture the benefits of the created game visualisation application in contrast to the BIM visualisation application by addressing model understanding, interactivity and model experience, collaborative work facilitation and level of interest. In terms of model understanding, all the participants implied that they were better able to understand the building model space, layout and information when visualised by the game approach. Participant D stated that "The game visualisation is much better compared to the BIM visualisation as you have shown it to me ... It allows the user freedom to choose what to look at and when, walk in through doors opening, leap over obstacles, see the different components, furniture and fixtures installed in the building and have an appreciation of space". Participant A noted that a better appreciation of space implied that suggestion can be given in regards to the placement of required objects (Furniture, kitchen equipment etc.) and their positioning.

In comparison to the game visualisation approach, participants described BIM visualisation as "Passive" (Participant B), where the information presented is prefixed to what the architect/designer wants the recipients to see, and not what the recipients want to see. The participants further implied that game visualisation gives the "freedom to explore" (Participants B, C, D, E, \& F), where the user is in charge of the whole process, and chooses what part of the structure to observe at any angle (human eye scale at human viewpoint) and distance (close/far).

The game approach offered more in terms of interactivity to experience the model via keyboard controls and "immersion is a given with the game approach because as you interact with system you are immersed in it" (Participant A). Whereas with BIM the participants just sat and watched, so there was no interactivity. Participant $\mathrm{C}$ further 
stated "as a human when you put yourself inside the design space, you can see the place better. The game also communicates better information, for example you see how the doors are functioning as if they were in the real world". The general view from participants was that interaction with the building model enhanced the visualisation process by adding dynamics, and an element of reality to the experience unlike the static BIM visualisation approach. Participant F commented "with BIM it is just that amount of time, so the only way you could interact is going back to a certain video frame and pausing it".

In terms of collaborative work facilitation and communicating needs within the project team, the majority of responses implied that the game approach would help better, since after a building model is visualised in an interactive free to explore manner, it would be easier to communicate client requirements based on proper appraisal of the project. Nevertheless, Participant B suggested that the choice of approach depends on the time a client would get to spend on the experience and learning the controls, stating "for a client that is very short in time to give feedback, the BIM approach would be better, because the client would be irritated if she/he needs to learn a lot of things while they are not curios to learn anything, there is no time and they just want the project delivered".

The majority of participants would prefer the game visualisation approach when involved in a construction project in regards to the aforementioned benefits. This is mostly in the case where the involvement is in a client's position, such that the client requirements can be determined and communicated. However, when involved as a designer several participants shared a similar view to Participant E who stated "the BIM model would be more appropriate, because as a designer I would want to present information that people would understand, and that information would be in the form that can communicate what I want them to see". These findings suggest that BIM is more beneficial to designers, whereas the game approach could work better for the less experienced, given enough time to explore and be familiar with the approach. Additionally, some participants suggested that the BIM approach could be used initially to present concept designs, then as the design gets more complex the game approach could be used to complement the initial. The benefits discussed through interview findings show consistency with observation findings, and add upon them supporting the idea that game visualisation can serve to enhance a user's experience and understanding via interactive applications, enhancing collaborative work amongst project parties.

\subsection{Barriers to implementing game engines for construction}

\section{Findings from Observation}

The game developed under this project was faced with barriers limiting the development of a wider range of applications and ensuing benefits. It was intended that the BIM model would be automatically imported from Revit into Unity via a coded plugin and that it would support multiple users allowing communication. Moreover, it was intended that the game would allow users to make alterations to the building models and have these changes automatically reflect on the model both on Revit and Unity. The commonly applied process pipeline of exporting BIM models from Revit into Unity (see Figure 3) was tested with several models, yet the results were always plain and without texture so an alternative approach had to be explored and implemented using IFC file format. However, this limited the choice of BIM model since the free version of the Tridify tool is limited to a 30MB file size (Tridify, 2019). 


\section{Findings from Interviews}

Most participants noted that with the BIM, the inability to visualise internal spaces would impact their perception of what is presented and their ability to answer questions that would compare the BIM and game visualisation approaches. Participants were asked by the author, i.e. interviewee to bear that in mind to be fair in answering the comparative questions.

Nevertheless, several participants stated that due to their industry experience and having seen BIM walkthroughs before, they are able to appreciate both BIM and the game visualisation approaches. Participant A stated "with BIM visualisation I am fairly able to understand, probably due to my experience, I am more able to appreciate what is being presented even if it is just the exterior". Therefore, it can be assumed that for the most part the answers given in response to assessment questions provide a fair evaluation of the two approaches, whilst considering a small degree of benefit to the game approach.

During the interview sessions held, all but two participants were unfamiliar with the game controls, requiring the interviewee to present the game visualisation developed as per the interviewee's request after they have explored the game initially. The game approach requires a certain level of experience and familiarity with the controls to make the process efficient. Asserting this fact, participant B stated, "it requires experience, Psychomotricity, and knowledge to use all the buttons and functions, which is not difficult, but not completely intuitive for a person who is not used to games". Participant $\mathrm{C}$ further added that "It could be very time consuming to visualise a complex project with many levels and many rooms especially for someone who has no experience, so maybe the game approach is more suitable for simple projects". It may be argued that in larger scale project, directions can be added via the script system and the game interface to better guide the users around the building space. However, this was not considered in this project due to the small scale of the case study BIM model adopted and the limited scope of application development.

\section{CONCLUSION}

The game developed offered users interactivity with a BIM model (adopted as a case study) via the application of walkthrough enabling model exploration freely with intuitive keyboard controls, and the door opening/closing application when triggered by the player enabling immersive interior visualisations. These applications are beneficial to project managers when presenting building design information to clients/users who are less experienced with design software, enabling model exploration in a free, interactive manner, to ultimately provide feedback and note any issues.

Other potential applications were deduced from both interview findings and observations, presented as potential functionalities that could be developed using the script/code systems included: fire evacuation simulation, safety education simulations, procurement and tendering simulations, interactive visualisations, design review by multiple users, visualising offsite construction processes, and basic 3D editing/alteration applications. Further applications included: costing/valuation application, services / offices / crowd control design simulation, and an energy analysis application. Responses from interviews strongly suggested that incorporating VR technology into game visualisation and employing better quality graphics in future 
applications, would allow users to have a better appreciation of building space, and hence enhance the design visualisation experience.

The benefits of game engine application were evaluated through careful observation of the game runs and implementation process, and considering sources in literature. These were validated and positively enhanced by interview participant responses. The game could enhance visualisation \& interactivity, project understanding and stakeholder collaboration. Furthermore, the literature suggests that game engines compared to VR or AR technologies, provided an efficient way to create virtual environments, at reduced costs, development time and technical difficulty. So also, scripts/codes help to create applications that are flexibly compared to what is available using standard in game engines.

The barriers of game engine application include lack of standard framework to reuse BIM models into game engines; limited knowledge and experience using C\# programming language; and difficulty in developing complex applications due to hardware and software requirements

The framework used to develop the game application can be a means to reuse Revit BIM models into the Unity3 game engine in future. The proposed framework should facilitate the adoption of game engines applications in construction activities to enhance project understanding and collaboration and enable further research.

\section{REFERENCES}

Abanda, F. H., Vidalakis, C., Oti, A. H. and Tah, J. H. M. (2015) 'A critical analysis of Building Information Modelling systems used in construction projects', Advances in Engineering Software, 90, pp. 183-201.

Ahmed, S. (2018) 'A Review on Using Opportunities of Augmented Reality and Virtual Reality in Construction Project Management', Organization, Technology, and Management in Construction, 18(10), pp. 1839-1852.

Aydin, S. and Schnabel, A. M. (2014) 'Survey on the visual communication skill of BIM Tools'. The Association for Computer-Aided Architectural Design Research in Asia (CAADRIA), Hong Kong, pp. 337-346.

Baiden, B. K., Price, A. D. F. and Dainty, A. R. J. (2006) 'The extent of team integration within construction projects', International Journal of Project Management, 24, pp. 13-23.

Barwise, K. et al. (2010) 'Productivity in The Buildings Network: Assessing The Impacts of Building Information Models', Report to the Built Environment Innovation and Industry Council, Volume 1, pp. 1 - 82. Available at: http://buildingsmart.org.au/wpcontent/uploads/2014/03/BIM Economic Stud y_Final- Report 290ct2010.pdf (Accessed: 15 April 2019).

Bates, R. and Khasawneh, S. (2007) 'Self-efficacy and college students' perceptions and use of online learning systems', Computers in Human Behavior, 23(1), pp. $175-191$.

Behzadi, A. (2016) 'Using augmented and virtual reality technology in the construction industry', American Journal of Engineering Research, 5(12), pp. 350-353.

Bhoir, S., and Esmaeili, B. (2015) 'State-of-the-art review of virtual reality environment applications in construction safety', In: AEI 2015, Milwaukee, WI, March 24-27, pp. 457-468. 
Bille, R. et al. (2014) 'Extending Building Information Models Into Game Engines', Proceedings of the 2014 Conference on Interactive Entertainment, 14(1), pp. 1 - 8. Doi: 10.1145/2677758.2677764.

BSI. (2010). Constructing The Business Case - Building Information Modelling. London: BSI Corporate. CA: Sage istepi

Chi, H.L., Kang, S.C., and Wang, X. (2013) 'Research trends and opportunities of augmented reality applications in architecture, engineering, and construction', Automation in Construction, 33, pp. 116-122.

CryEngine (2019) CryEngine Features. Available at: https://www.cryengine.com/features (Accessed: 7 March 2019).

Cyra, R. (2018) Virtual Reality Is Changing The Construction Industry. Available at: https://gineersnow.com/industries/how-virtual-reality-changes-constructionindustry (Accessed: 6 March 2019).

Dickinson, J. et al. (2011) 'Game-based trench safety education: development and lessons learned', Journal of Information Technology in Construction (ITcon), 16(2011), pp. 119-134.

Doughty, M.A. and O'Coill, C. (2005) 'Computer game technology, collaborative software environments and participatory design', In IADIS International Conference: Web Based Communities 2005. 23-25 February 2005, Algarve, Portugal, pp. $1-4$.

Dunleavy, M. and Dede, C. (2014) 'Augmented reality teaching and learning', in: Spector, J., Merrill, M., Elen, J., and Bishop, M. (ed.) Handbook of Research on Educational Communications and Technology. Springer, New York, NY, pp. 735-745.

Edwards, G., Li, H. and Wang, B., (2015) 'BIM Based Collaborative and Interactive Design Process Using Computer Game Engine for General End-users', Visualization in Engineering, 3(4), pp. 1 - 17. Doi: 10.1186/s40327-015-

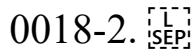

El Nimr, A, and Mohamed, Y. (2011) 'Application of gaming engines in simulation driven visualization of construction operations', Journal of Information Technology in Construction (ITcon), 16(2011), pp. 23-38.

Fernandes, K. et al. (2006) 'Adoption of virtual reality within construction processes: a factor analysis approach', Technovation, 26(1), pp.111-120.

Garrison, D. R. and Kanuka, H. (2004) 'Blended learning: Uncovering its transformative potential in higher education', The Internet and Higher Education, 7(2), pp. 95-105.

$\mathrm{Gu}, \mathrm{N}$. et al. (2009) 'Evaluating the use of 3D virtual worlds in collabora-tive design learning', In the 13th international conference on Computer Aided Architectural Design (CAADFutures). St Leonards Sydney: Icon. Net Pty Ltd, pp. $51-64$.

Handel, O. et al. (2015) 'Dynamic Visualization of Pedestrian Simulation Data', Forum Bauinformatik. Aachen, Germany, January 2015. Technical University of Munich, pp. 1 - 9.

Herrlich, M. (2007) 'A tool for landscape architecture based on computer game technology', In 17th International Conference on Artificial Reality and Telexistence, pp. 264-268. is.epe.

Hevner, A., March, S., Park, J., and Ram, S.(2004) Design Science in Information Systems Research," MIS Quarterly (28:1) 2004, pp 77-105.

Holness, G. V. R. (2006) 'Building Information Modelling', ASHRAE Journal, 48(8), pp. $38-46$. 
Jacobson, J. and Lewis, M. (2002) 'Game engines in scientific research', Communications of the ACM, 45(1), pp. 27-31. iLẸ?

Jayanam (2016) Unity3D: How To Open And Close Doors. Available at: https://www.youtube.com/watch?v=jKe2zMFa2mw (Accessed: 31 March 2019).

Kamara, J.M., Anumba, C.J. and Evbuomwan, N.F. (2002). Capturing client requirements in construction projects. Thomas Telford.

Kamat, V. R. et al., S. (2010) 'Research in visualization techniques for field construction' Journal of Construction Engineering and Management, 137(10), sisepp. 853-862.

Kehily, D. and Underwood, J. (2015) 'Design Science: Choosing an appropriate methodology for research in BIM', In proceedings of CITA BIM Gathering 2015. Dublin Institute of Technology, Dublin, 12-13 November. Dublin: ARROW, pp. 257-263.

Kotzé P. , Van der Merwe A. and Gerber A. (2015) Design Science Research as Research Approach in Doctoral Studies. Twenty-first Americas Conference on Information Systems, Puerto Rico, 2015

(Accessed: 26 February 2019).

Lin, KY, Son, J, and Rojas, E. (2011) 'A pilot study of a 3D game environment for construction safety education', Journal of Information Technology in Construction (ITcon), 16(2011), pp. 69-84.

Lin, T.J. et al. (2013) 'An investigation of learners' collaborative knowledge construction performances and behavior patterns in an augmented reality simulation system', Computers \& Education, 68, pp. 314-321.

Loijens, L. W., Brohm, D., and Domurath, N. (2017) 'What is augmented reality?' in: Loijens, Leanne W. S. (ed.) Augmented Reality Consumers. Wageningen Academic Publishers, Wageningen, p. 356.

Marks, S., Windsor, J., and Wünsche, B. (2007) 'Evaluation of game engines for simulated surgical training', In Proceedings of the 5th International Conference on Computer Graphics and Interactive Techniques in Australia and Southeast Asia. GRAPHITE 2007, 1 - 4 December. New York: NY, pp. 273-280.

McLeod, S. (2015) Observation Methods. Available at: https://www.simplypsychology.org/observation.html (Accessed: 22 March 2019).

Merlo, A., Dalco, L. and Fantini, F. (2012) 'Game engine for cultural heritage: New opportunities in the relation between simplified models and database', 18th International Conference on Virtual Systems and Multimedia (VSMM), pp. $623-628$.

Microsoft (2019) Microsoft XNA Game Studio 4.0. Available at: https://www.microsoft.com/en-us/download/details.aspx?id=23714 (Accessed: 7 March 2019).

Mitchell, J. et al. (2012) 'A strategy for the focussed adoption of building information modelling and related digital technologies and processes for the Australian built environment sector', National Building Information Modelling Initiative, Volume 1, pp.1-26. Available at: http://buildingsmart.org.au/wpcontent/uploads/2014/03/NationalBIMIniativeR eport 6J une2012.pdf (Accessed: 6 March 2019). 
Murphy, E. and Coleman, E. (2004) 'Graduate students' experiences of challenges related to participation in online asynchronous discussions', Canadian Journal of Learning and Technology, 30(2), pp. 29-46.

Nguyen, D.L., Ogunlana, S.O. and Lan, D.T.X. (2004) 'A study on project success factors in large construction projects in Vietnam', Engineering, Construction and Architectural Management, 11(6), pp. 404-413.

Nguyen, T.P. and Chileshe, N. (2013) 'Revisiting the critical factors causing failure of construction projects in Vietnam', In: Smith, S.D and Ahiaga-Dagbui, D.D (Eds) Procs 29th Annual ARCOM Conference, 2-4 September 2013, Reading, UK, Association of Researchers in Construction Management, pp. 929-938.

Parise, S. and Crosina, E. (2012) 'How a mobile social media game can enhance the educational experience', Journal of Online Learning and Teaching, 8(3), pp. $209-219$. is

Park, C.S. et al. (2013) 'A framework for proactive construction defect management using BIM, augmented reality and ontology-based data collection template', Automation in Construction, 33, pp. 61-71.

Peffers, K. et al. (2008) 'Design science research methodology for information systems research', Journal of Manage Information Systems, 24(3), pp. 45-77.

Pejoska, J. et al., (2016) 'LEpe.' Social augmented reality: Enhancing context-dependent communication and informal learning at work', British Journal of Educational Technology, 47(3), pp. 474-483.

Preda, M., and Jovanova, B. (2013) 'Avatar interoperability and control in virtual worlds', Signal Processing: Image Communication, 28(2), pp. 168-180. is[ep:

Reddy, K. P. (2012) BIM for Building Owners and Developers: Making a Business Case for Using BIM on Projects. Hoboken, New Jersey.: John Wiley \& Sons, Inc.

Rüppel, U, and Schatz, K. (2011) 'Designing a BIM-based serious game for fire safety evacuation simulations', Adv Eng Inform, 25(11), pp. 600 - 611. is.p.

Sabbagh, M. (2015) The Important difference between first-person and third-person games. Available at:

https://www.gamasutra.com/blogs/MichelSabbagh/20150827/252341/The_im portant_differences_between_firstperson_and_thirdperson_games.php (Accessed: 8 May 2019).

Serror, et al. (2008) 'Shared Computer-aided structural design model for construction industry (infrastructure)', Computer-Aided Design, 40(7), pp. 778-788.

Shemla, A. and Nachmias, R. (2006) 'How do lecturers integrate the Web in their courses? Web- supported courses at Tel-Aviv University', In Proceedings of World Conference on Educational Multimedia, Hypermedia and Telecommunications 2006. Chesapeake, VA: Association for the Advancement of Computing in Education, pp. 347-354.

Shiratuddin, MF, and Thabet, W. (2011) 'Utilizing a 3D game engine to develop a virtual design review system', Journal of Information Technology in Construction (ITcon), 16(2011), pp. 39-68.

Smith, S. P., and Trenholme, D. (2009) 'Rapid prototyping a virtual fire drill environment using computer game technology’, Fire Safety Journal, 44(4), pp. 559-569.

Tomala, M. (2017) Adoption of Emerging Technology in UK Construction Industry: Adoption Factors and Their Interdependence. MSc Thesis. Oxford Brookes University. 
Trenholme, D. and Smith, S. P. (2008) 'Computer game engines for developing firstperson virtual environments', Virtual Reality, 12(3), pp. 181-187.

Tridify (2019) Tridify Convert \& Unity BIM Tools (Version 2.0) [Computer program]. Available at: https://assetstore.unity.com/packages/tools/utilities/tridify-bimtools-125779 (Downloaded: 3 February 2019).

Unity (2019) The world's leading real-time creation platform. Available at: https://unity3d.com/unity (Accessed 7 March 2019).

VIM AEC (2017) Virtual Information Modelling Complete Revit BIM to Immersive Real-time in a few minutes. Available at: https://www.vimaec.com/vim/ (Accessed: 10 March 2019).

Wang, W.C. et al. (2014) 'Integrating building information models with construction process simulations for project scheduling support', Automation in Construction, 37, pp. 68-80.

Wang, X., and Dunston, P. S. (2007) 'Design, strategies, and issues towards an augmented reality-based construction training platform' Journal of Information Technology in Construction (ITcon), 12(25), pp. 363-380.

Whyte, J. (2003) 'Industrial applications of virtual reality in architecture and construction', Journal of Information Technology in Construction (ITcon), 8(4), pp. 43-50.

Xue, et al. (2018) 'Analyzing collaborative relationships among industrialized construction technology innovation organizations: A combined SNA and SEM approach', Journal of Cleaner Production, 173, pp. 265-277.

Yan, W., Culp, C. and Graf, R. (2011) 'Integrating BIM and gaming for real-time interactive architectural visualization', Automation in Construction, 20(4), pp. $446-458$.

Zaher, M., Greenwood, D., and Marzouk, M. (2018) 'Mobile augmented reality applications for construction project', Construction Innovation, 18(2), pp. $152-166$.

Zyda, M. (2005) 'From visual simulation to virtual reality to games', IEEE Computer, 38(9), pp. 25-32.

\section{APPENDICES}

\section{APPENDIX A: Script Written To Activate The Door Opening Application}

using System.Collections;

using System.Collections.Generic;

using UnityEngine;

public class DoorScript : MonoBehaviour

\{

private Animator_animator = null;

// Start is called before the first frame update void Start() 


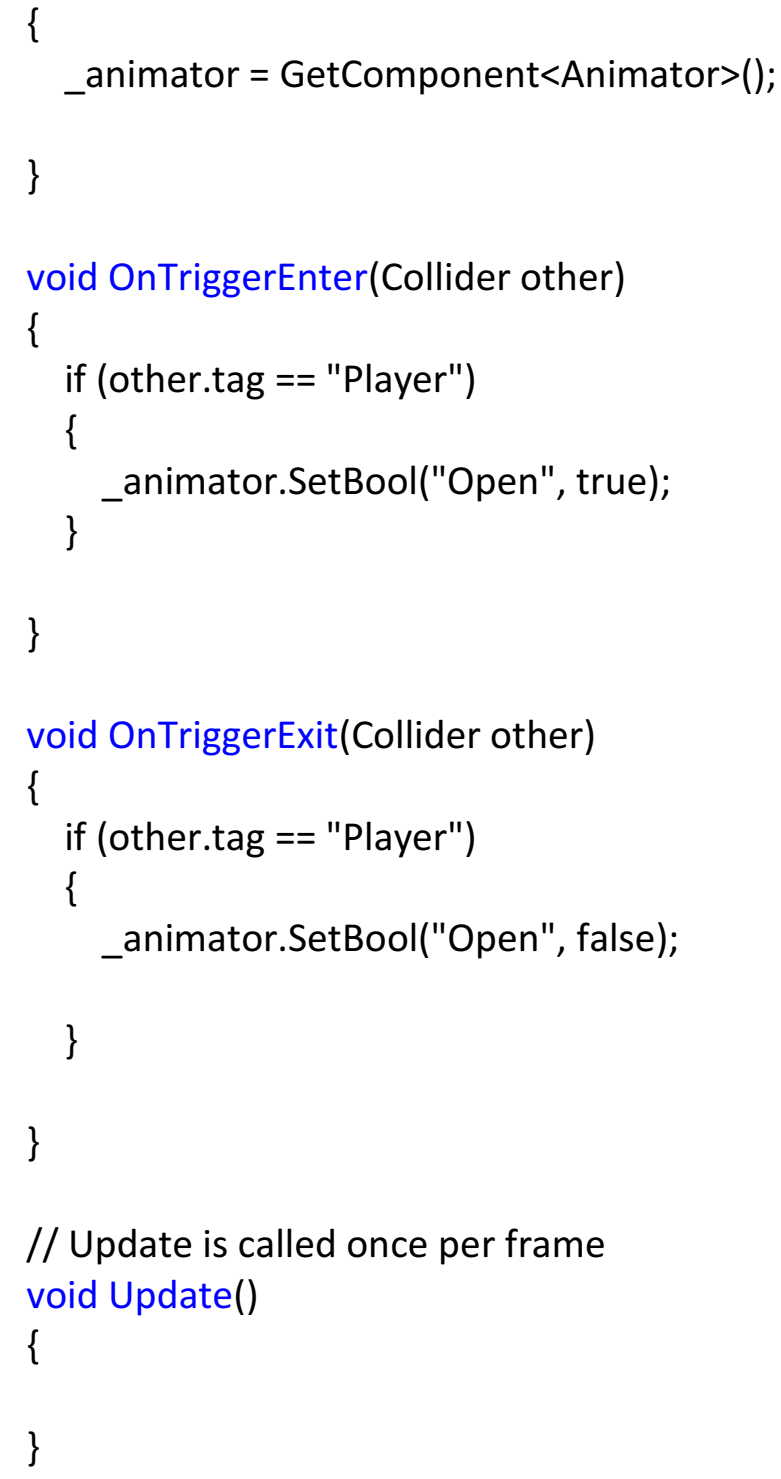

>> To run the game: Download the link files and open 'ModelTest3.exe' $<<$

\section{APPENDIX C: Link to the BIM Visualisation Walkthrough Developed}

BIM - Revit Walkthrough Video Link (Runs on any Operating System):

https://1drv.ms/f/s!AqKSPHBDV1y7ddDqduvE bNZ1c4

>> To view the video: Download and Play 'BIM Revit Walkthrough.avi' << 
